\title{
The Impact of Task-planning and Gender on the Accuracy of Narrations Composed by Iranian EFL Learners
}

\author{
Hamid Reza Haghverdi \\ Islamic Azad University, Khorasgan (Isfahan) Branch, Isfahan, Iran \\ Reza Biria \\ Islamic Azad University, Khorasgan (Isfahan) Branch, Isfahan, Iran \\ Hamid Reza Khalaji \\ Islamic Azad University, Khorasgan (Isfahan) Branch, Isfahan, Iran
}

\begin{abstract}
The purpose of this study was to investigate whether planning in writing tasks affect the accuracy of the written narrations or not. To do so, 90 EFL full time male and female students all between the ages of 21 and 27 were pooled out of a population of 120 through giving them the SAT practice test. They were divided into three groups of thirty. All of the groups were assigned the same written task which was a narration based on six-picture series. However, the conditions of task implementation differed. The no-planning group was served as the control group, while the within-task planning and strategic planning groups were considered as experimental groups. The accuracy was measured by counting the number of error-free clauses and accurately used verbs. The result of the study showed that the strategic planning group outperformed the other groups.
\end{abstract}

Index Terms - task, within-task planning, no planning, strategic planning, narration

\section{INTRODUCTION}

Undoubtedly every teaching approach will affect the skills to be learned. Writing skill has also been affected by various teaching methods. The methods and approaches have undergone noticeable changes. In the 1970s, Communicative Language Teaching (CLT) approach was introduced (Brumfit \& Johnson, 1979). The goal of CLT was similar to earlier methods such as Audio Lingual Method (ALM) or oral-situational method. In fact, all of them sought to develop the ability to use language in communication. The difference was the means through which the goal was achieved. The earlier methods viewed language as a set of linguistic systems while CLT was based on a theory of developing communicative competence (Ellis, 2003). The term 'task' was introduced instead of 'communicative activity' during the 1980s (Rubdy, 1998). Tasks were widely used in both communicative and traditional approaches of language teaching. The way of teaching in which tasks are incorporated is referred to as task-supported language teaching (TSLT) (Ellis, 2003). Skehan (2003) refers to it as the 'weak version' of task based instruction. The strong version is referred to as task-based language teaching (TBLT).

First, TBLT focused on fluency while ignoring other aspects of language such as complexity and accuracy. Skehan (1996a) believed that the implementation of TBLT does not develop the learners' linguistic repertoire effectively. As a result, the idea of fluency or accuracy became a dilemma for the teachers as well as learners. Yuan (2001) argued that traditional approaches failed to develop learners' fluency and TBLT did not satisfy the learners' needs for accurate language use. Perhaps the reason behind this dilemma is that humans have limited attentional resources (Schmidt, 1990).

Different proposals were developed to account for this problem. One of them was how pre-, mid-, and post-task activities can be designed to ensure an effective balance between form and meaning in TBLT (Skehan, 1996a, 2003; Foster \& Skehan, 1999; Yuan, 2001).

One line of research focused on the effects of pre-task planning on language production, and how it influences the ways attention is used; particularly in relation to form-meaning balance. Skehan (1996 a) suggests that giving learners the opportunity to plan for their production prior to performing tasks may encourage them to focus on form and as a result create a balance in attentional resources between form and meaning while performing a task.

Another line of research focused on the effects of within-task or online planning (i.e. planning taking place while performing a task) on language production and whether or not it is more useful than strategic planning in terms of creating a balance between attention to form and attention to meaning. It seems that both types of planning develop learners' oral and written production, but it is not clear which one is more effective. In the following section a brief account of task planning has been mentioned. 
Wigglesworth (1977) in a study concludes that planning time is a term which has been the focus of attention in many studies in both first and second language production and as Sanagarun (2001) argues planning time is still "an important feature of language production". Most of these studies have their roots in L1 research aiming at developing cognitive models of oral production with planning as one of their components (Crookes, 1989). Givon (1979) and Ochs (1979) came to this conclusion that L1 planned discourse would promote L2 development.

Givon (1979) compared planned and unplanned L1 oral and written productions and the result of his comparison was two modes of production: the "pragmatic mode" and the "syntactic mode". According to Givon (1979) adult L1 production has a loose coordination. This matter is comparable to the pragmatic mode. Givon (1979) also concludes that adult L1 planned production can be compared with the syntactic mode with high subordination and high use of grammatical morphology. Ochs (1979) investigated the effects of L1 planned versus unplanned discourse from a psycholinguistic point of view. The result of her study was that a number of features which exist in the discourse of three to four-year-old children show themselves in adults' unplanned discourse. She found that planned discourse was based on knowledge which had been acquired or learned later in life. She hypothesized that whenever planning time is not available speakers rely on their early-acquired morphosyntactic structures and discourse skills.

On the other hand, Hayes and Gradwohl Nash (1996) came to this conclusion that the more time spent on a task, the more the effects of planning would appear. They focused their study on L1 writings and the result was that "planning is neither more nor less valuable than other writing activities" (p. 53). Thus, it can be said that strategic planning affords learners more time overall. Of course, the studies used holistic ratings of writings as measures.

Some studies on L1 and L2 planning have been carried out concerning the level of consciousness involved in each. In some studies like those of Farch and Kasper (1983) it has been mentioned that planning in L1 is subconscious and highly ballistic. Perhaps the reason is that L1 speakers have ready-made plans that reduce their processing load. On the other hand these ready-made plans may not be available to many L2 speakers especially at the beginner level and will result in an increased pressure on working memory of the speakers (Mehnert, 1998). It seems that L2 speakers must construct their own plans in order to compensate for the pressure imposed on their working memory. To do so, they should have a strong cognitive control which can be reduced through planning. The nature of planning is complicated. Thus it is better to first consider the definition of the term.

\section{The definition of planning}

Generally, planning is referred to as "a goal-oriented mental activity that people engage in to achieve a particular objective" (Newell \& Simon, 1972). According to Yuan (2001), planning involves the allocation of attentional resources and the regulation of cognitive processes. Das, Kar, and Parilla (1996) define planning as follows:

[Planning] is oriented to future, and may include the creation and selection of problems, as well as the anticipation of a sequence of actions to solve them. (p. 54)

Foss and Hakes (1978) argue that planning in production involves the formulation of ideas, the choice of appropriate lexical items, and organizing them "in a suitable semantic and syntactic framework" (p. 170). Wendel (1997) believes that planning involves the retrieval and organization of an utterance. Ochs (1979) also differentiates planned from unplanned discourse in terms of the presence or lack of thought preparation and discourse organization. Ellis (2005), on the other hand, considers the types of linguistic devices used in planning which he refers to as "a problem solving activity". According to Ellis, the aim of planning is "to affect the audience in the desired way" (p. 3).

In the literature on task planning, speech planning and writing planning have been taken into account. Clark and Clark (1977) refer to two types of activities involved in speaking: planning and execution. They found that planning is an umbrella tem which involves discourse, sentence, and even constituents. These elements are interwoven in the execution of a language act. Farch and Kasper (1983) differentiate planning phase from execution phase. According to them, the planning phase involves searching the linguistic repertoire and selecting the rules and items that meet the communicative needs of the speaker. On the other hand, in the execution phase these rules and items are executed to satisfy the original goal.

Considering planning in writing, Hayes and Gradwohl Nash (1996) regard it as a kind of reflection which should be accompanied with other reflective processes such as decision making and inferencing. It has also been argued that the difference between planning and other reflective processes is that the environment of planning is completely different from that of the task. Hayes and Gradwohl Nash (1996) distinguish between two types of planning. The first type is process planning which is related to the writer and the strategies he/she uses to accomplish a given task. The second type is text planning which is related to the content and form of writing. Still another distinction has been made between different types of writing planning on the basis of the discoursal levels they involve. Whalen and Menard (1995) refer to types of planning such as pragmatic planning, textual planning, and linguistic planning. Pragmatic planning deals with the identification of audience and reason for writing, and developing a given topic. Textual planning, on the other hand, involves achieving coherence between idea sequences. Finally, linguistic planning involves the writer's attempts to solve a linguistic problem to formulate an idea.

Planning has been linked to interlanguage (IL) development. Selinker (1972) coined the term interlanguage. It refers to the developmental language between L1 and L2. Interlangauge has its specific features. Corder (1981) believes that interlanguage is a mixed language that involves some features of the learner's L1 and some features of his L2; but it is neither pure L1 nor L2 and has its own features. Ellis (1987) proposed that planning allows the learner to access the 
linguistic forms that have not been fully automated. Skehan (1996) also stated that planning frees up attentional resources and redirects them on the forms of language. As it was seen, there are various attitudes toward planning both considering writing and speaking. In the following section, different kinds of planning will be taken into account.

\section{Types of task planning}

Ellis (2005) classifies task planning into two main types. The difference is in the time of planning. The first type of planning is pre-task planning in which planning takes place before performing the task. In this type of planning as Schmidt (2001) calls it, there is 'preparatory attention' which helps in performing actions with greater accuracy and speed. The second type of planning is within-task planning. Each of these types is divided into two other types.

Pre-task planning can be divided into rehearsal and strategic planning. In rehearsal planning, learners have the opportunity to "perform the task before the "main performance"" (Ellis, 2005, p. 3). In this type of planning, the first performance of the task is considered as a preparation for the main performance. Strategic planning, on the other hand, involves learners' preparation of the content of the task they are going to perform. This type of planning is the focus of the present study. In strategic planning, learners "have access to the actual task materials" (Ellis, 2005, p.3).

Within-task planning has been also divided into pressured and unpressured planning. In the first one, learners are not usually given enough time to plan on-line, while in unpressured within-task planning they are given enough time to plan online.

The classification can be continued. There are still other types of task planning that may occur with both main types of task planning. The first one is related to the amount of guidance that is given to learners (i.e. unguided vs. guided task planning). In unguided planning, learners will be on their own in their planning; however, they may be given some advice on what to plan and how to plan (Ellis, 2005). The second sub-type is on the basis of source of planning. Foster and Skehan (1999) found that different sources of planning have an effect on the outcome of planning. The sources may include teacher-led, group-based, and solitary planning. The third sub-type of planning is the foci of planning which is related to the orientation of planning in terms of form and content. As a result, planning may be content-focused, formfocused, or both form and content-focused (Sangarun, 2001). It seems that this subtype is somehow related to the first sub-type (i. e. unguided vs. guided task planning) since guidance usually is on the form, on the content or both.

Various combinations of principal and sub-types of planning have been the focus of different studies. Some of the studies will be mentioned in the following sections of the present dissertation.

In the present research, the researchers focused on the application of task planning on writing. To do so, they limited their study to the accuracy of narrative tasks written by Iranian EFL learners. Since the focus of the present study is writing, it will be better to consider one of the models of writing as a basis of the explanations related to the present study.

\section{B. Kellog's Model of Writing}

Kellog's (1996) model involves three basic systems (Ellis \& Yuan, 2004). Each system involves two processes. The first system is Formulation and involves (i) 'planning' in which goals are set and ideas are organized, and (ii) 'translation' in which lexical units and syntactic frames are selected; then they are phonologically and graphologically represented to be ready for execution. The second system is Execution and involves (i) 'programming' where the output from translation is converted into production schema, and (ii) 'executing' which is the actual production of a sentence. The third system is Monitoring which involves (i) 'reading' in which the writer reads his/her production, and (ii) 'editing' in which the writer attends to either micro aspects (such as linguistic errors) and/or macro aspects (such as text organization) of the text. According to Kellogg, the Execution system which is responsible for problem solving and mental calculation is involved in all sub-processes with the exception of executing in which there is no need for controlled processing.

However, Ellis (2005) believes that Kellogg considers an adult, native-like automaticity in handwriting and typing which might not be present in L2 learners with limited proficiency, especially those whose L1 employs a different script. Therefore, he concludes that the execution system would be called upon during executing by some L2 writers.

\section{The nature of writing}

Writing stands out among the four basic skills of language learning. Olshtain (1993) explores the special status of writing within the framework of language teaching. She identifies:

"The skill of writing enjoys special status. It is via writing that a person can communicate a variety of meanings to close or distant, known or unknown readers. Such communication is extremely important in the modern world, whether the interaction takes the form of a traditional paper and pencil writing or the most advanced electronic mail. As Olshtain (1993, p.235) puts it, "writing as a communicative activity needs to be encouraged and nurtured during the language learners' course of study”.

Olshtain addresses the prominence of composition with reference to various audiences and the miscellaneous of its use. But, Chastain points to the significance of writing with respect to its relationship with language proficiency and level of education. According to Chastain, writing is a kind of communication skill as well as a unique asset in the process of second language learning. He further argues that "writing with its unique features contributes to overall language learning. Both aspects of writing are important in the typical language class and both can serve to reinforce the other. Moreover, "writing is the distinctive ability of educated people" (Chastain, 1988, p.244). 
Irrespective speaking, writing is a much slower process. Raimes (1983) draws our attention to a fact that everybody learns speech as a mother tongue, but he/she is not able to acquire how to read or write. All forms of communication such as facial expressions, gestures, all non-verbal forms are transformed to linguistic and mechanical forms in writing, and one needs to be informed of all these forms.

Speakers may violate the grammar rules, but writing will be remained as a valid document and is subject to different forms of criticism. Consequently, writing is the last skill in the sequence to develop, should be learned by study in a longer process of time. Harris (1969) states: "writing as a complex skill involves the spontaneous practice of a number of very different abilities, some of which are never fully achieved by many students even in their native language" (p.68) Writing, and specifically academic writing, requires training, instruction, practice, experience and purpose." (Grabe and Kaplan, 1996, p.6)

Based on the previous studies in this domain, the following research questions were formed.

\section{RESEARCH QUESTIONS}

1) Is there any significant difference between Iranian EFL learners' language accuracy when they have the opportunity to plan a written narrative task both in advance and while writing than when they have no opportunity to do so?

2) Is there any significant difference between the performance of EFL Iranian males and females concerning the accuracy of their written tasks?

In order to answer the posed questions, a study was carried out as explained in the following section.

\section{METHODOLOGY}

This section will describe the methods which have been used to investigate the research questions.

\section{A. Research Design}

The design of the present study is a mixed one since there are both statistical analysis and interviews with the participants. The between-group factor in the study is planned condition, with three conditions (no-planning, strategic planning, and within-task planning).To measure the effects of planned condition on learners' written products, two way ANOVA (Two Way Analysis of Variance) study was conducted.

\section{B. Participants}

The participants in the study were 90 EFL full-time students. They were studying at Islamic Azad universities of Malayer, Hamedan, and also the state university of Malayer. They were between the ages of 21 and 27 years. There were 46 males and 44 females in the research who had studied English for at least two academic years. Some of them had participated in English classes of institutes. They had successfully passed language skill courses (i.e. writing, reading, listening, and speaking) in addition to grammar and vocabulary use.

\section{Instruments}

This section provides a description of the instruments used in the study, which includes: pretest materials, writing tasks, task conditions, scoring rubrics used to rate learners' written products, and scoring procedures. Pretest material which included fifty items was selected from multiple-choice a SAT practice test which is a valid, reliable and official test series of English used to test the writing skills in English. This test was selected because it is inexpensive, easy to administer, and easy to score objectively. Raimes (1987) argued that linguistic proficiency is not the only factor to impact evaluation of L2 written text. It is evident, however, that if grammatical knowledge is viewed as "a set of linguistic resources from which learners select forms based on appropriateness for meaning, for audience, and for textual demands" (Frodesen \& Holten, 2003, p. 157), learners' L2 linguistic proficiency and writing proficiency in the evaluation of their written products are inseparable to a certain extent.

Additionally, as an indirect test of writing, the grammar section of the selected test is expected to evaluate learners' knowledge of writing sub-skills, including grammar and sentence structure, which are supposed to underlie writing ability (Knoll, 1998). In the present study, L2 knowledge as an indicator of learners' proficiency level is narrowly defined in terms of grammatical competence under Bachman's (1990) communicative language ability framework. Grammatical competence, constituting one part of language competence, refers to the ability to control the formal structure of language and to recognize a grammatically correct sentence. Therefore, grammatical competence includes relatively independent capabilities such as the knowledge of vocabulary, morphology, syntax, and phonology or graphology at the sentence level. A certain amount of linguistic knowledge is considered to be a prerequisite for constructing a coherent text.

The scores of the proficiency test were calculated and entered into ANOVA analysis and based on the obtained results 90 participants were selected for the study.

The term 'task' has been used in different studies on written narratives (Ellis, 1987; Yuan, 2001; and Ellis \& Yuan, 2004). The task used in the present study is a story-narration based on a series of pictures from Heaton (1975). The pictures are designed to elicit a story, and each story requires interpretation on the part of the learner. The learner has to 
study the pictures and generate his/her ideas on the first draft. To do this, he/she may need collaboration and sharing ideas with other classmates.

\section{Task conditions}

In the present research planning was operationalized at three levels: (a) no planning (NP); (b) strategic planning (SP); and (c) within-task planning (WTP). The control group was the no-planning condition (NP) in which participants were given no time for planning and were asked to write at least 150 words. In order to set up the appropriate time during which they are required to finish the task, the pilot study involving similar participants had been carried out.

The fastest time found for completing the task was 25 minutes. This was time was given to complete the task in the main study to avoid within-task planning on the part of the participants.

The first experimental group was the strategic planning condition (SP) in which participants were given ten minutes to plan for their narrations prior to performing the task. They were also asked to write at least 150 words. No detailed guidance was provided for planning, but the participants were asked to plan their narratives in terms of content, organization, and language following (Crookes, 1989; Skehan \& Foster, 1996, 1997, 1999; Wendel, 1997; Yuan, 2001; Yuan \& Ellis, 2003; and Ellis \& Yuan, 2004). They were allowed to write notes on a sheet of paper, but were asked not to write the whole story, and the notes were taken away before they performed the task. Again, based on the findings of the pilot study, participants under this planning condition were allowed 25 minutes to complete the task.

The second experimental group was the within-task planning condition (WTP) in which participants were required to start performing the task immediately, but were given as much time as needed to complete the task. The only difference was that they were not given any time to plan for the task in advance, but they were allowed unlimited time to plan while performing the task. There was a different condition. The participants were not required to write a minimum of 150 words because "this may be interpreted as requiring them to write quickly" (Ellis \& Yuan, 2004: 70). Task instructions were in Persian to avoid misunderstanding on the part of the learners.

Retrospective interviews

After performing the written narratives, three participants were randomly selected from each group for a retrospective interview with the researcher. The purpose of this interview was to investigate how participants used the planning time they were given, what they concentrated on, and whether or not they made use of what they planned.

\section{Methodology of Data Analysis}

\section{Measures}

Based on what Yuan (2001) and Ellis and Yuan (2004) have stated, the following measures for planning (independent variable) and accuracy (dependent variable) were considered:

Independent variables: planning and gender

Planning is the independent variable of the study. There are two planning conditions in the present study: strategic planning, and within-task planning. Planning was measured as follows:

1. Length of time: the total number of minutes on task was calculated for each participant.

2. Words: the total number of words produced by each participant was calculated.

3. Syllables: the total number of syllables produced by each participant was calculated.

The purpose of counting the syllabuses was to consider the length of words. It was not clear that whether or not participants under the within-task planning condition were engaged in significant within-task planning. Therefore, these measures were used "to see if the participants had performed the task in the expected planning condition" (Yuan, 2001, p. 61).

Also the gender of the participants who were either males or females was considered as an independent variable in the present study.

\section{Dependent variable: Accuracy}

Accuracy refers to "the ability of the learner to use the target language according to its norms" (Edwards, C. and Willis, J., 2005). It has been measured as follows:

1. Error-free clauses: the ratio of error-free clauses to the total number of clauses used was calculated.

2. Accurately used verbs: the percentage of accurately used verbs in tense, modality, and subject-verb agreement was counted within each narrative.

\section{RESUltS AND DisCUSSIONS}

In the following tables, the results of the two-way ANOVA are shown. 
TABLE1.

THE SCORES OF PARTICIPANTS *GENDER

\begin{tabular}{|ll|l|l|l|l|}
\hline Participants & Gender & & \multicolumn{3}{l|}{$95 \%$ Confidence Interval } \\
\cline { 5 - 6 } & & Mean & Std. Error & Lower Bound & Upper Bound \\
\hline No Planning Task & Male & 72.187 & .622 & 70.950 & 73.425 \\
& Female & 72.786 & .665 & 71.462 & 74.109 \\
\hline Within-task Planning & Male & 74.867 & .643 & 73.588 & 76.145 \\
& Female & 74.067 & .643 & 72.788 & 75.345 \\
\hline Strategic Planning & Male & 75.867 & .643 & 74.588 & 77.145 \\
& Female & 76.400 & .643 & 75.122 & 77.678 \\
\hline
\end{tabular}

As it can be inferred from table 1, the scores which are the result of assessing the accuracy of the written tasks and are given on the scale of 100, are not significantly different between males and females who participated in the study. The interpretation is that as far as gender is considered, there are not any significant differences in the accuracy of written tasks generated by Iranian EFL learners.

\begin{tabular}{|c|c|c|c|c|}
\hline \multirow[t]{2}{*}{ Gender } & \multirow[b]{2}{*}{ Mean } & \multirow[b]{2}{*}{ Std. Error } & \multicolumn{2}{|c|}{ 95\% Confidence Interval } \\
\hline & & & Lower Bound & Upper Bound \\
\hline $\begin{array}{l}\text { Male } \\
\text { Female }\end{array}$ & $\begin{array}{l}74.307 \\
74.417\end{array}$ & $\begin{array}{l}367 \\
.376\end{array}$ & $\begin{array}{l}73.577 \\
73.671\end{array}$ & $\begin{array}{l}75.037 \\
75.164\end{array}$ \\
\hline
\end{tabular}

According to the table 2, the mean of the participating males in the study was 74.307; while, that of the females was 74.417. The minute difference between the means proves the neutrality of gender effect on the performance of males and females.

TABLE 3:

THE SCORES OF THE PARTICIPANTS IN THE THREE GROUPS

\begin{tabular}{|l|l|l|l|l|}
\hline Participants & & \multicolumn{3}{l|}{$95 \%$ Confidence Interval } \\
\cline { 5 - 6 } & Mean & Std. Error & Lower Bound & Upper Bound \\
\hline No Planning Task & 72.487 & .456 & 71.581 & 73.393 \\
Within-task Planning & 74.467 & .455 & 73.563 & 75.371 \\
Strategic Planning & 76.133 & .455 & 75.229 & 77.037 \\
\hline
\end{tabular}

As the table 3 illustrates, the means of the scores of all of the three groups participating in the study are different. However the significance of these mean differences was not clear. Thus the researchers ran a Post Hoc test analysis to ensure whether the observed differences were significant or not. Table 4 summarizes the results of this analysis.

TABLE 4:

THE RESUlTS OF POST HOC TESTS

\begin{tabular}{|ll|l|l|l|}
\hline (I) Participants & (J) Participants & & \\
& & Mean Difference (I-J) & Std. Error & Sig. \\
\hline No Planning Task & Within-task Planning & $-2.00^{*}$ & .643 & .007 \\
& Strategic Planning & $-3.67^{*}$ & .643 & .000 \\
\hline Within-task Planning & No Planning Task & $2.00^{*}$ & .643 & .007 \\
& Strategic Planning & $-1.67^{*}$ & .643 & .030 \\
\hline Strategic Planning & No Planning Task & $3.67^{*}$ & .643 & .000 \\
& Within-task Planning & $1.67^{*}$ & .643 & .030 \\
\hline
\end{tabular}

As it can be inferred from table 4, all of the mean differences between the three groups are statistically significant. The planning groups have outperformed the no-planning group as far as the accuracy of written narrations is concerned. According to the table 4, the greatest mean difference was observed between the means of strategic planning and noplanning groups. Thus, on the basis of table 3, we may argue that the strategic group had the best performance than the other group; however, the within-task planning group was better than the no-planning group as far as the accuracy of their written tasks is considered.

TABLE 5:

COMPARISON BETWEEN PARTICIPANTS AND GENDER

\begin{tabular}{|l|l|l|l|l|l|}
\hline Source & Type III Sum of Squares & df & Mean Square & F & Sig. \\
\hline Participants & 199.501 & 2 & 99.750 & 16.089 & .000 \\
Gender & 274 & 1 & .274 & .044 & .834 \\
Participants * Gender & 9.335 & 2 & 4.667 & .753 & \\
Error & 520.795 & 84 & 6.200 & & \\
Total & 498320.000 & 90 & & & \\
Corrected Total & 732.622 & 89 & & & \\
\hline
\end{tabular}


According to the table 5, it can be said that the F-value for participants is 16.089 which is significant at 0.000 ; and 0.044 for the gender which is significant at 0.834 . The combination of participants and gender yields an F-value of 0.753 which is significant at 0.474 . In the next part, the profile plot of the comparison between males and females is brought. Then the research questions have been answered.

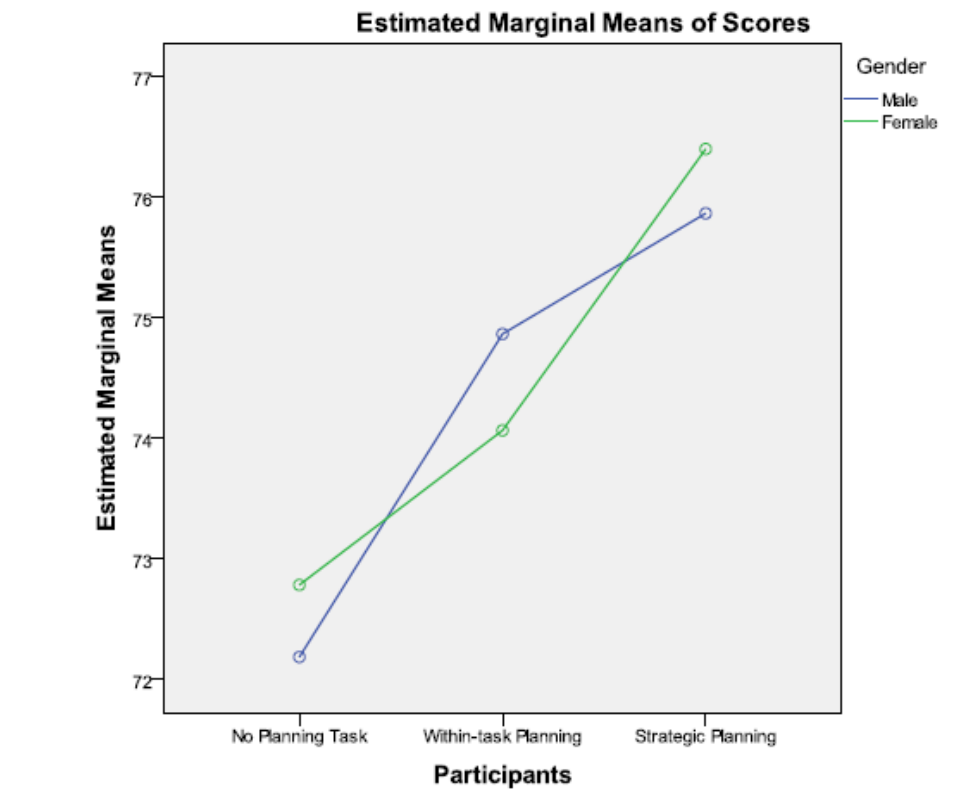

Profile Plot 1: the Comparison between the Scores of Males and Females in the Three Groups

As it is shown in the plot, the mean difference between the three groups cannot be attributed to the gender of the participants. Rather, the difference is because of the planning implemented before or during the task performance.

Following the research questions have been answered.

Research question (1): Is there any significant difference between Iranian EFL learners' language accuracy when they have the opportunity to plan a written narrative task both in advance and while writing than when they have no opportunity to do so?

According to the table 4, the mean differences for no-planning (NP) and within-task planning (WTP) groups; WTP and strategic planning (SP) groups; as well as SP and NP groups are 2.00, 1.67, and 3.67 respectively. These differences are significant at $0.007,0.030$, and 0.000 respectively. Thus it may be inferred that planning has had a positive effect on the accuracy of narrations produced by Iranian EFL learners.

Research question (2): Is there any significant difference between the performance of EFL Iranian males and females concerning the accuracy of their written tasks?

There is not any significant difference between the performances of males and females regarding the accuracy of their written narration tasks. It can be inferred from the table 4 that the F-value for the groups is 16.089 which is significant at 0.000 . It means that planning has significantly affected the performances of the experimental groups. However as far as gender is regarded, the F-value is 0.44 and significant at 0.835 which is more than 0.05 . It is not significant enough to reject the hypothesis. Accordingly it may be inferred that gender does not have any significant effects on the mean differences between control and experimental groups.

\section{DISCUSSION}

Perhaps the significant differences between the groups can be attributed to the storage and processing of information in the long term and sort term memories. Long term memory has an important role in storing information. Skilled writers as compared with unskilled ones can cope with the different writing conditions. It may be argued that the participants who gained the best scores are able to store their knowledge of writing in their long term memory. On the contrary, those participants who have been rather unsuccessful may store the information in their short term memory. Thus the most successful group, which is the strategic group in the present study, may have had the time to focus on both working memory and long-term memory at the same or different times. They have used the time of planning to retrieve the related information they needed and put the needed data on papers; thereby to enhance their writings.

Previous studies have investigated the effects of planning on the quality of written tasks and have found that planning results in more accurate writing (e.g., Yuan, 2001; Ellis \& Yuan, 2004).

In the present study, the strategic planning group outperformed the no-planning group and within-task planning. Most of the participants in the NP group reported that if they had been given some time before starting to write, they would have reflected on their tasks and their tasks would have been much better. Thus, time seems to be a very important factor even if it is not used for planning. The students need the time to reflect on their writings more. 
Generally, the SP group outperformed the NP group regarding the dependent variable. Planning and translation are the two stages of the formulation process in Kellogg's model. The formulation process of Kellogg's model places the heaviest burden on short term memory.

In the first stage of the formulation process, writers set goals, think up ideas related to the goals, and organize their ideas. These ideas are retrieved from the learner's long term memory. Therefore, it can be resulted that in every writing process both short term memory and long term memory are involved. The second stage, translating, involves a linguistic level of representation in which the pre-verbal message resulting from the planning stage is transformed into a verbal message. In this stage, "the writer activates semantic, syntactic, phonological, and orthographic sub-processes" (Kellogg, 1996: 59).

With regards to the planning stage of Kellogg's model, the notes sheets of the SP group show planning that resembles children's pattern in planning (Bereiter \& Scardamalia, 1987) in which conceptual planning notes, evaluative statements, and structural markers were less than those in other groups. This group simply generated complete sentences that were edited into a final draft when writing. Thus, it is apparent that the SP group because of their access to both short and long-term memory at the time of planning and doing the task had been more successful than the no-planning group. The SP group also had also time management in their planning and writing. At the time of planning, they focused on the main ideas, retrieving the right words, outlining, drafting, and organizing the sentences. While writing, the participants were paying their attention to the sequence of sentences, punctuation, using the correct verb forms and language in general. Therefore, since the SP group had distributed their time and at a time had focused on one area of writing, it seems that they had freed up some space in their memories which had caused them to have more informative and accurate writings.

Difficulties in translating, on the other hand, were due to the inability to manage the heavy demands of storage and processing as a result of low proficiency in lower level writing skills. Translating an idea into an acceptable sentence involves the phonological loop. Phonological representations of the words selected in a syntactic frame are stored in the short-term store of the loop. In addition to the phonological loop, translating also demands resources of the central executive when the writer must struggle to find the right words and sentence structures (Kellogg, 1996). The noplanning group, on the other hand, because of time limitation and lack of planning time had a lot of problems. They did not have access to their long term memory since their time was so limited. They could not even collaborate and share their ideas with each other. McCutchen (2000) claims that trade-offs exist between the storage and processing functions of working memory because of resource limitations within the system. That is, when more resources are devoted to processing, fewer resources are available for storage and vice versa. The NP group had to spend most or perhaps all their time processing the language and structure, thus the storage function of their short-term memory had perhaps very limited.

Both skilled and unskilled writers resort to short term memory resources to construct the sentences that comprise their texts. However, the fluent sentence generation processes of skilled writers, combined with their rich knowledge bases, enable them to link developing sentences to extensive knowledge stored in their long term memory.

\section{CONCLUSION}

As it was stated in the previous parts, the results of the two-way ANOVA procedure indicated that planning whether strategic or within-task planning affects the accuracy of the written tasks. These results are in line with earlier investigations of the effects of planning either on oral performance or on written performance (de Bot, 1996; Franken \& Haslett, 2002; Shi, 1998; Foster \& Skehan, 1996; Wendel, 1997). Thus, these results tend to support the claim that the planning process eased the processing load during task completion and enabled learners to produce high quality texts.

The results of the study confirmed that planning in the L2 writing process enabled learners to lower their cognitive load during task completion and to yield high quality writing with regard to their scores. Remarkably, collaboration with a partner in the planning process was more effective in generating specific examples and details to help learners develop their own ideas. According to what was stated, it can be concluded that planning is highly effective in fostering the writing ability of learners.

One of the conclusions of the study is that the type of planning also plays an important role in improving the writing skills of the learners. The within-task planning in Iranian contexts is not as effective as strategic as the research suggests. In other contexts, the results differ. Generally, collaboration before implementing the task and on the basis of management is fruitful in Iranian contexts. If the students have the time to share their ideas, if they are given enough input whether pictorial, oral, and even written, the products of their writing will be much informative.

Perhaps the most important conclusion can be attributed to the differences between within-task and strategic planning. In the study, the strategic planning group because of time distribution and time management had the best performance. Thus, it can be concluded that in the writing classes, time management must be practiced a lot so that the students learn how to divide their time in accordance with the tasks they are going to perform.

\section{REFERENCES}

[1] Bachman, L. F. (1990). Fundamental considerations in language testing. New York: Oxford University Press. 
[2] Bereiter, C., \& Scardamalia, M. (1987). The psychology of written composition. Hillsdale, NJ: Lawrence Erlbaum Associates, Inc.

[3] Brumfit, C. and K. Johnson. (1979). The communicative approach to language teaching. Oxford: Oxford University Press.

[4] Chastain, K. (1988). Developing Second Language Skills: Theory and Practice. $3^{\text {rd }}$ ed Orlando, Florida: Harcout Brace Jovanovich.

[5] Clark, H. and G. Clark. (1977). Psychology and language: an introduction to psycholinguistics. New York NY: Harcourt, Brace, Jovanovich.

[6] Corder, S. P. (1981). Error analysis and interlanguage. London: Oxford University Press.

[7] Crookes, G. (1989). Planning and interlanguage variation. Studies in Second Language Acquisition. 11, 367-383.

[8] Das, J. P., Kar, B. C., \& Parrilla, R. K, (1996). Cognitive planning: the psychological basis of intelligent behavior. New Delhi: Sage.

[9] De Bot, K. (1996). A bilingual production model: Levelt's 'Speaking Model' adapted. Applied Linguistics, 13: 1-24.

[10] Ellis, R. (1987). Interlanguage variability in narrative discourse: Styles shifting in the use of past tense. Studies in Second Language Acquisition, 9, 1-20.

[11] Ellis, R. (2003). Task-based language teaching and learning. Oxford: Oxford University Press.

[12] Ellis, R., \& F. Yuan (2004). The effects of planning on fluency, complexity, and accuracy in second language narrative writing. Studies in Second Language Acquisition, 26, 59-84.

[13] Ellis, R. (2005). Planning and task-based performance: theory and research. In Ellis, R. (Ed.) Planning and task performance in a second language. Amsterdam: John Benjamins.

[14] Farch, C. and G. Kasper. (Eds). (1983). Strategies in interlanguage communication. London: Longman.

[15] Foss, J. and D. Hakes (1978). Psycholinguistics: an introduction to the study of language. Englewood Cliffs, NJ: Prentice-Hall.

[16] Foster, P. \& Skehan, P. (1996). The influence of planning and task type on second language performance. Studies in Second Language Acquisition, 18, 299-323.

[17] Foster, P. \& Skehan, P. (1999). The influence of source planning and focus of planning on task-based performance. Language Teaching Research, 3, 215-247.

[18] Franken, M., \& Haslett, S. (2002). When and why talking can make writing harder. In S. Ransdell \& M. Barbier (Eds.), New directions for research in L2 writing (pp. 209-230). Dordrecht, the Netherlands: Kluwer Academic.

[19] Givon, T. (1979). On understanding grammar. New York: Academic Press.

[20] Grabe, W., \& Kaplan, R. B. (1996). Theory and practice of writing. Essex: Pearson Education Limited.

[21] Harris, D. P. (1969). Testing English as a Second Language. New York: Mcgraw-Hill.

[22] Hayes, J. and J. Gradwohl Nash. (1996). On the nature of planning in writing. In C. Levy and S. Ransdell (Eds.). The science of writing. Mahwah NJ: Lawrence Erlbaum.

[23] Heaton, J. (1975). Beginning composition through pictures. London: Longman.

[24] Kellog, R. (1996). A model of working memory in writing. In C. Levy and S. Ransdell (Eds.). The science of writing. Mahwah NJ: Lawrence Erlbaum.

[25] Knoll, B. (1998). Assessing writing abilities. Annual Review of Applied Linguistics, 18, 219-240.

[26] Mehnert, U. (1998). The effects of different lengths of time for planning on second language performance. Studies in Second Language Acquisition, 20, 83-108.

[27] Newell, A. and H. Simon. (1972). Human problem solving. Englewood Cliffs, NJ: Prentice Hall.

[28] Ochs, E. (1979). Planned and unplanned discourse. In Givon, T.(Ed.). Syntax and Semantics. New York: Academic Press, 5180.

[29] Olshtain, E. (1993). Functional tasks for mastering the mechanics of writing and going Just beyond. In M. Celce-Murcia (Ed.), Teaching English as a Foreign Language. $2^{\text {nd }} E d, 235-265$.

[30] Raimes, A. (1983). Anguish as a second language? Remedies for composition teachers. In A. Freedman, I. Pringle, \& J. Yalden (Eds.), Learning to write: First language/second language (pp. 258-272). Harlow, England: Longman.

[31] Rubdy, R. (1998). Key concepts in ELT: task. English Language Teaching Journal, 52 (3), 264-65.

[32] Sangarun. J. (2001). The effects of pre-task planning on foreign language performance. Doctoral thesis, University of Toronto, Canada.

[33] Schmidt, R. (2001). Attention. In Robinson, P. (Ed.), Cognition and second language instruction. Cambridge: Cambridge University Press.

[34] Schmidt, R. (1990). The role of consciousness in second language learning. Applied linguistics, 11: 17-46.

[35] Selinker, L. (1972). Interlanguage. International Review of Applied Linguistics, 10: 209- 31.

[36] Shi, L. (1998). Effects of prewriting discussions on adult ESL students' compositions. Journal of Second Language Writing, 7 , 319-345.

[37] Skehan, P. (1996a). A framework for implementation of task-based instruction, Applied Linguistics, 17, 38-62.

[38] Skehan, P. (2003). Task based instruction. Language Teaching, 36(1): 1-14.

[39] Skehan, P. (1996b) Second language acquisition research and task-based instruction. In J. Willis \& D. Willis (Eds.) Challenge and change in language teaching (pp. 17- 30) Oxford: Macmillan Heinemann.

[40] Skehan, P. and P. Foster (1997). Task type and task processing conditions as influences on foreign language performance. Language Teaching Research 1: 185-211.

[41] Skehan P. and P. Foster (1999). The influence of task structure and processing conditions on narrative retellings. Language Learning 49(1): 93-120.

[42] Wendel, J. N. (1997). Planning and second-language narrative production. Doctoral Thesis, Temple University.

[43] Whalen, J. and N. Menard. (1995). L1 and L2 writers' strategic and linguistic knowledge: A model of multiple-level discourse processing. Language Learning, 45: 381-418.

[44] Wigglesworth, G. (1997). An investigation of planning time and proficiency level on oral test discourse. Language Testing, 14, 85-106. 
[45] Yuan, F. (2001). The effects of planning on language production in task-based language teaching. Doctoral thesis, Temple University.

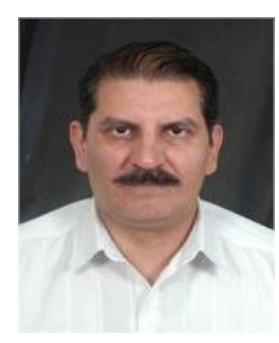

Hamid Reza Haghverdi is a member of the Academic Staff with the rank of Assistant Professor at Khorasgan Islamic Azad University in Isfahan. He is the Head of the English Department. He has taught phonetics and phonology, discourse analysis and practical teaching to MA students. He has also offered Language Laboratory courses, together with Testing to BA students. He has also cooperated with Bandar Abass Islamic Azad University to present MA courses. He knows three languages, Persian, English and some Arabic.

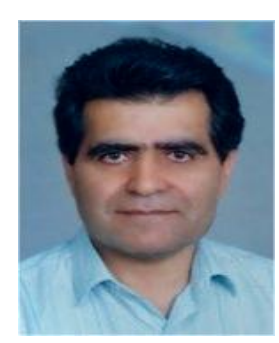

Reza Biria is also a faculty member of English Language Teaching Department, Islamic Azad University, Khorasgan (Isfahan) Branch. He is an assistant professor at Khorasgan branch. He holds a $\mathrm{PhD}$ in applied linguistics. Dr. Biria's interests are language testing, research methodology, linguistics, and teaching methodology. He has published a lot of articles and books. Dr. Biria has participated in several seminars and conferences and is an experienced professor of English.

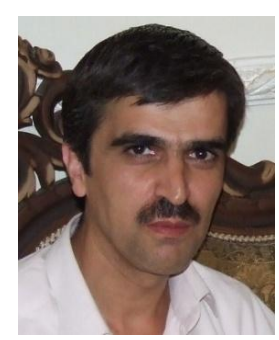

Hamid Reza Khalaji was born in Malayer, Islamic Republic of Iran, in 1971. He is currently a PhD student studying Teaching English as a Foreign Language at Islamic Azad University, Khorasgan (Esfahan) Branch, Iran.

He has been teaching English for 13 years at different universities like Islamic Azad Universities of Malayer, Tuyserkan, Hamedan, Arak, and also at Payam-e-Noor university of Malayer.He participated in an International conference in Poland in 2007 and presented a lecture on "The Generation Effect Phenomenon and Learning English Grammar". He has published a book entitled General English for University Students,(Malayer, Hamedan province, Kereshmeh publications, 2006). 